\title{
Софья Федотова
}

\section{ОПРЕДЕЛЕНИЕ ТЕМБРА ПЕВЧЕСКОГО ГОЛОСА: КЛАССИФИКАЦИЯ ГОЛОСОВ ПО СИСТЕМЕ ҒАСН}

Тембр - это природная окраска звука, в связи с этим, для грамотной работы с певческим голосом необходимо опираться на его естественную природу, искореняя недостатки и раскрывая достоинства. Почему же так важно «услышать» истинную природу голоса? Пение «не своим голосом» чревато быстрой утомляемостью голосового аппарата, вплоть до фониатрических проблем, а также невозможностью полностью раскрыть потенциал голоса. Вокальная методика содержит критерии, помогающие в определении тембра голоса, а также классификации певческих голосов. Тем не менее, однако, в силу разнообразия голосов, тембров и физических возможностей певцов к каждому голосу необходим индивидуальный подход. Кроме того, проблема определения типа голоса может осложняться дефектами звукообразования, полностью избежать которых удается немногим начинающим вокалистам.

Основная классификация голосов формировалась постепенно и сложилась к XVII в., по мере развития оперного искусства вокальными исследователями выделялись новые подтипы внутри каждого типа голоса.

В статье продемонстрированы лишь некоторые из существующих подходов к классификации типов певческих голосов, выбор которых был обусловлен личным интересом и доступностью источников для автора.

Тембр - одно из важнейших качеств певческого голоса, именно тембр придает голосу индивидуальное, особенное звучание. Тембр зависит от обертонов, сопровождающих звук, и их относительной силы. Характеризуя звук, говорят о глухом тембре, звонком, теплом, ясном. 


\section{Классификация голосов по европейской системе Fach}

Система Fach (нем. «предмет», «ящик»), разделяющая певцов по категориям в зависимости от типа голоса, физических данных и актерского дарования, возникла еще в начале XIX в., но на данный момент получила особое распространение в европейских репертуарных театрах. Информация об этой классификации изложена на основе иностранного источника: статьи педагога по вокалу Университета Мемфиса доктора Кайла Фэррила. Автор одного из основных источников, посвященных системе Fach, американский дирижер Ричард Болдри составил список, включающий более 3500 ролей более чем в 1000 операх.

Система Fach базируется на основной классификации голосов, но оперирует более узкими категориями. Если певца отнесли к определенному «фаху», от него ожидается, что он может исполнить любую роль из своей категории, хотя автором отмечается, что одна и та же роль может быть отнесена к нескольким «фахам». Слово ящик, как название этой системы, может объясняться тем, что каждый оперный певец имеет свой метафорический «ящик», в который складывает исполняемые партии.

Итак, перейдем к классификации.

Сопрано.

Субретка, диапазон от до первой октавы до до третьей. Примеры партий: Папагена («Волшебная флейта» Моцарта), Джанетта («Любовный напиток» Доницетти), Барбарина («Свадьба Фигаро» Моцарта).

Описание: часто играют второстепенных персонажей - сестер или подружек главных героинь, легкий, гибкий голос, с хорошим верхним регистром и чистым центром, нижний регистр может быть слабо выражен. Необходимы хорошие актерские данные, проработка образа важна в связи с тем, что субретка как бы оттеняет ведущих персонажей.

Легкое лирическое колоратурное сопрано. Диапазон: до первой октавы - $\phi a$ третьей. Примеры партий: Норина («Дон Паскуале» Доницетти), Зербинетта («Ариадна на Наксосе» Штрауса), Деспина («Так поступают все женщины» Моцарта).

Описание: сильный голос с довольно резким тембром и хорошим верхним регистром, это может быть главный или второсте- 
пенный персонаж, автор также отмечает любопытную характеристику этого «фаха» - способность изобразить невинность.

Легкое лирическое сопрано. Диапазон: до первой октавы - до диез третьей октавы. Примеры партий: Сюзанна («Свадьба Фигаро» Моцарта), Нанетта («Фальстаф» Верди), Марселина («Фиделио» Бетховена).

Описание: голос с хорошим и сильным верхом, имеющий мало красок в нижнем регистре, обладающий изысканной фразировкой. Это всегда молодые девушки, этот голос характеризуется как нечто среднее между субреткой и полным лирическим сопрано.

Полное лирическое колоратурное сопрано. Диапазон: до первой октавы - $p a$ третьей. Примеры партий: Джульетта («Ромео и Джульетта» Гуно), Фрау Флут («Виндзорские проказницы» Николаи).

Описание: имеет большой диапазон, насыщенный тембр и более выраженные нижние ноты, по сравнению с предыдущими типами, но при этом также обладает подвижностью. Этот «фах» часто встречается в барочных операх.

Полное лирическое сопрано. Диапазон: до первой октавы - до диез третьей октавы. Примеры партий: Мими («Богема» Пуччини), Чио-чио Сан («Мадам Баттерфляй» Пуччини), Тоска («Тоска» Пуччини).

Описание: голос с красивым, теплым, тембром, выраженным и богатым обертонами средним и нижним регистром.

Легкое драматическое колоратурное сопрано. Диапазон: до первой октавы - фа третьей. Примеры партий: Норма («Норма» Беллини), Лючия («Лючия ди Ламмермур» Доницетти), Виолетта («Травиата» Верди).

Описание: голос имеет сильный верх, прорезающий и сияющий тембр, сочетает гибкость лирического сопрано с весом драматического. Этот «фах» наиболее востребован и универсален.

Легкое драматическое сопрано (спинто). Диапазон: до первой октавы - си бемоль третьей октавы. Примеры партий: Джизельда («Ломбардцы в первом крестовом походе» Верди), Амелия («Симон Бокканегра» Верди), Сантуцца («Сельская честь» Масканьи).

Описание: Голос меньшего диапазона, но большего наполнения, в верхнем регистре может звучать напряженно. Наиболее часто ассоциируется с итальянским веризмом конца XIX в. 
Полное драматическое колоратурное сопрано. Диапазон: до первой октавы - $\not a$ третьей октавы. Примеры партий: Анна Болейн «Анна Болейн» Доницетти, Донна Анна («Дон Жуан» Моцарта), Донна Эльвира («Дон Жуан» Моцарта).

Описание: довольно редкий голос, так как партии требуют сильного и теплого тембра на всем диапазоне, верх блестящий и подвижный, но при этом не резкий.

Полное драматическое сопрано. Диапазон: си малой октавы - си бемоль второй октавы. Примеры партий: Кундри («Парсифаль» Вагнера), Дидона («Дидона и Эней» Перселла).

Описание: насыщенный голос с блестящим металлическим тембром, используемый в немецком романтическом и постромантическом репертуаре. Обладает сильным верхом, крепким средним регистром, богатым резонансом.

Мецичо сопрано.

Легкое лирическое мецио сопрано. Диапазон: си малой октавы си второй октавы. Примеры партий: Орловский («Летучая мышь» Штрауса), Керубино («Свадьба Фигаро» Моцарта), Гензель («Гензель и Греттель» Хумпердинка).

Описание: голос грациозный, яркий, лиричный, в операх часто исполняет роли юношей. Легкие и игривые персонажи, требующие хорошей физической формы.

Полное лирическое мецицо сопрано. Диапазон: соль малой октавы - си второй октавы. Примеры ролей: Секст («Милосердие Тита» Моцарта), Шарлотта («Вертер» Массне), Дульсинея («Дон Кихот» Массне).

Описание: голос мягкого и теплого тембра, гибкость при этом не является приоритетом, французские композиторы начала XIX в. использовали его для драматических ролей.

Драматическое мецио. Диапазон: си малой октавы - си бемоль второй октавы. Примеры партий: Азучена («Трубадур» Верди), Графиня («Пиковая дама» Чайковского), Брангена («Тристан и Изольда» Вагнера).

Описание: голос большой, с металлическим и темным тембром, имеет достаточную силу для исполнения мощных кульминационных моментов. Используется в русских операх, а также в операх Верди и Вагнера. 
Лирическое контральто. Диапазон: соль малой октавы - фа второй октавы. Примеры партий: Эрда («Золото Рейна» Вагнера), Герцогиня («Сестра Анжелика» Пуччини), Ульрика («Бал Маскарад» Верди).

Описание: Это самый низкий женский «фах», с глубоким, темным тембром и меньшей гибкостью, чем меццо-сопрано. Партии этого «фаха» могут исполнять драматические меццо-сопрано.

Тенор.

Контртенор. Диапазон: фа малой октавы - ля второй октавы. Примеры ролей: Цезарь («Юлий Цезарь в Египте» Генделя), Аполлон («Смерть в Венеции» Бриттена), Оберон («Сон в летнюю ночь» Бриттена).

Описание: контртенор является относительно новым явлением, этот голос использует естественно резонирующий верхний регистр. Контртеноры часто поют произведения эпохи барокко, написанные для кастратов, но некоторые роли были специально написаны для этого голоса, например партия Оберона в опере Бриттена «Сон в летнюю ночь». Голос певцов менее драматичен, чем у кастратов, поэтому часто теряется некоторая театральная динамика.

Комический тенор. Диапазон: до малой октавы - си бемоль первой. Примеры партий: Горо («Мадам Баттерфляй» Пуччини), Бэппе («Паяцы» Леонкавалло).

Описание: связаны с оперой буффа XVIII в., имеют сильный средний регистр и хорошую подвижность, значительное внимание уделяется актерским способностям.

Легкий лирический тенор. Диапазон: до малой октавы - ре второй. Примеры партий: Феррандо («Так поступают все» Моцарта), Тамино («Волшебная флейта» Моцарта), Фентон («Фальстаф» Верди).

Описание: голос с мягким верхом и менее развитым низом, предпочтительно гибкий, важен для исполнения репертуара бельканто и партий в операх Моцарта, особенно зрелый певец получит роли в репертуаре Верди.

Полный лирический тенор. Диапазон: до малой октавы - до диез второй. Примеры партий: герцог («Риголетто» Верди), Рудольфо («Богема» Пуччини), Неморино («Любовный напиток» Доницетти).

Описание: крепкий, не слишком большой голос, обладающий уверенным легато, часто дополняет полное лирическое сопрано, в качестве примера приводится пара: Мими и Рудольфо. 
Драматический тенор (спинто). Диапазон: до малой октавы до второй. Примеры партий: Каварадосси («Тоска» Пуччини), Де Грие («Манон» Массне).

Описание: голос большего наполнения в сравнении с лирическим, обладает звонким, металлическим тембром.

Героический тенор. Диапазон: до малой октавы - си бемоль второй. Примеры партий: Тангейзер («Тангейзер» Вагнера), Зигфрид («Зигфрид» Вагнера), Отелло («Отелло» Верди).

Описание: этот пронзительный голос иногда называют Вагнеровский тенор. Его тесситура немного ниже его аналогов, но выше чем у баритона. Многие теноры, которые начинали как баритоны, переходят в этот «фах».

\section{Баритон.}

Легкий лирический баритон. Диапазон: до малой октавы - ля бемоль первой. Примеры партий: Фигаро («Свадьба Фигаро» Моцарта), Дон Жуан («Дон Жуан» Моцарта), Ко - ко («Микадо» Салливана).

Описание: гибкий голос, с сильным верхом, многие из ролей этого «фаха» часто исполняются характерными басами - баритонами в связи с тем, что их природа связана с оперой буффа, особенно в операх Моцарта. Британский композитор Гилберт Салливан писал для этого голоса партии главных героев в своих операх.

Полный лирический баритон (кавалер баритон). Диапазон: до малой октавы - фа диез первой. Примеры партий: Эскамильо («Кармен» Бизе), Папагено («Волшебная флейта» Моцарта), Фигаро («Севильский цирюльник» Россини).

Описание: крепкий голос, обладающий хорошим верхом, серединой и низами, фаворит французского репертуара.

Драматический баритон. Диапазон: ля большой октавы - фa диез первой. Примеры партий: Порги («Порги и Бесс» Гершвина), Яго («Отелло» Верди), Риголетто («Риголетто» Верди).

Описание: голос с темным бархатным звуком, имеющий достаточные возможности для исполнения ярких драматических кульминаций, его еще называют «Вердиевский баритон».

Бас.

Бас - баритон (характерный бас). Диапазон: ля бемоль большой октавы - $p a$ первой. Примеры партий: Лепорелло («Дон Жу- 
ан» Моцарта), Дулькамаре («Любовный напиток» Доницетти), Боттом («Сон в летнюю ночь» Бриттена).

Описание: это относительно новый «фах» для крепких, насыщенных и богатых обертонами голосов, часто это либо басы с хорошим верхним регистром, либо баритоны с хорошим нижним регистром. Автор отмечает, что для этих ролей очень важна характерность.

Комический бас. Диапазон: фа малой октавы - ми первой. Примеры партий: Дон Паскуале («Дон Паскуале» Доницетти), Фальстаф («Фальстаф» Верди).

Описание: ключевыми понятиями для понимания природы этого «фаха» являются юмор и хара́ктерность в сочетании с подвижностью голоса, что связано с распространенностью ролей для этого голоса в операх Доницетти и Россини. Голос характеризуется как ясный, теплый с множеством тембральных красок, применяемых в зависимости от желаемого эффекта.

Лирический бас. Диапазон: соль малой октавы - фа первой. Примеры партий: Зарастро («Волшебная флейта» Моцарта), Мазетто («Дон Жуан» Моцарта), Людовико («Отелло» Верди).

Описание: для этого голоса важна хорошая кантилена и верхний регистр.

Драматический бас. Диапазон: ми малой октавы - ми первой. Примеры партий: Банко («Макбет» Верди), Командор («Дон Жуан» Моцарта), Борис Годунов («Борис Годунов» Мусоргского).

Описание: голос темного тембра с наполненными, насыщенными, сильными резонирующими низами, способными прорезать оркестр, в этот «фах» входит бас - профундо.

Тембр певческого голоса - многогранное и сложное понятие, рассматриваемое исследователями в аспектах акустики, физиологии, специфики оперного пения и выразительности оперного образа. Вокальная методическая литература содержит определенные критерии для определения типа голоса, однако, ввиду разнообразия голосов, тембров и физических возможностей певцов, к каждому голосу необходим индивидуальный подход. Кроме того, проблема определения типа голоса может осложняться дефектами звукообразования, полностью избежать которых удается немногим начинающим вокалистам. 
Основная классификация голосов формировалась постепенно и сложилась к XVII в., по мере развития оперного искусства вокальными исследователями выделялись новые подтипы внутри каждого типа голоса.

В статье продемонстрированы лишь некоторые из существующих подходов к классификации типов певческих голосов, выбор которых был обусловлен личным интересом и доступностью источников для автора.

Отдельный раздел статьи посвящен используемой в Европе классификации оперных голосов по системе Fach, которая в некоторой степени схожа с классификациями мастеров итальянской школы и советских исследователей, но при этом является более дифференцированной, связывает подтипы голоса не только с тембральными характеристиками, но и разноплановыми актерскими навыками и фактурой певцов, а также, содержит примеры оперных партий, не распространенных на российской оперной сцене, что представляется автору интересным.

\section{Использованные источники}

1. Вишневская Г.П. Галина: История жизни. М. : Новости, 1991. 131 с.

2. Гарбузов Н.А. Процесс становления звуков как причина ладового движения. Теория многоосновности ладов и созвучий. Ч. 2. М., 1932. 198 с.

3. Гарсиа М. Советы по пению : учебное пособие / пер. Н.А. Александровой. СПб. : Планета музыки, 2014. 104 с.

4. Глинка М.И. Записки. Л. : Музгиз, 1953. 284 с.

5. Гонторенко Н.Б. Сольное пение: секреты вокального мастерства. 4-е изд. Ростов н/Д: Феникс, 2008. 183 с.

6. Гордеева Т.Ю. К истокам певческих школ. Вариант классификации // Вестник Кемеровского государственного университета культуры и искусств. 2013. № 23. С. 176-182.

7. Денисова Г.М. Основные постулаты российской вокальной школы на современном этапе развития музыкального искусства (певческий голос и методика его постановки) // Вестник культуры и искусств. 2006. № 1 (9). С. 120-129.

8. Дмитриев Л.Б. Основы вокальной методики. М. : Музыка, 1968. 338 с.

9. Евсеев Ф.Е. Школа пения. Теория и практика для всех голосов : учебное пособие. 2-е изд., стер. СПб. : Лань; Планета музыки, 2015. 80 с.

10. Зданович А.П. Некоторые вопросы вокальной методики. М. : Музыка, 1965. $148 \mathrm{c}$.

11. Иванова Е.К. Пути формирования и сохранения профессиональных качеств голоса // Вестник культуры и искусств. 2015. № 2 (42). С. 134-139. 
12. Котова Р.В. Исполнительская культура и формирование молодого певца-артиста. М. : Готика, 2006. 188 с.

13. Коткина И.А. Атлантов в большом театре: Судьба певца и движение оперного стиля. М. : Аграф; Большой театр, 2002. 336 с.

14. Кроуэст Ф.Дж. Советы певцам / пер. с англ. Е. Сергеевой. СПб. : Лань; Планета музыки, 2017. 80 с.

15. Ламперти Ф. Искусство пения по классическим преданиям. Технические правила и советы ученикам и артистам : учебное пособие. 2-е изд., испр. СПб. : Лань; Планета музыки, 2009. 192 с.

16. Люш Д.В. Развитие и сохранение певческого голоса. Киев : Муз. Украйина, 1988. $138 \mathrm{c}$.

17. Морозов В.П. Искусство резонансного пения. Основы резонансной теории и техники. М. : МГК им. П.И. Чайковского, 2002. 496 с.

18. Морозов В.П. Тайны вокальной речи. Л. : Наука, 1967. 208 c.

19. Николаев Д.В. Феномен оперного голоса // Известия государственного педагогического университета им. А.И. Герцена. Ч. 1: Общественные и гуманитарные науки. 2007. № 7 (43). С. 245-247.

20. Силантьева И.Г. Путь к интонации: Психология вокально-сценического перевоплощения. М. : КМК, 2009. 644 с.

21. Стулова Г.П. Факторы педагогического воздействия на тембр певческого голоса // Музыкальное искусство и образование. 2014. № 4 (8). С. 90-104.

22. Теплов Б.М. Психология музыкальных способностей. М.; Л. : АПН РСФСР, 1947. $336 \mathrm{c}$.

23. Чишко О.С. Певческий голос и его свойства. Л. : Музыка, 1966. 50 с.

24. Юссон Р. Певческий голос. М. : Музыка, 1974. 132 с.

25. Ferril Kyle The Fach System origin, function, and the dangers of perception. URL: // https://www.academia.edu/

\section{Sofia Fedotova}

DEFINITION OF A TIMBRE OF A SINGING VOICE:

FACH VOICE CLASSIFICATION

Musical almanac of Tomsk State University, 2020, no. 10, pp. 112-123.

doi: 10.17223/26188929/10/11

Timbre of a singing voice is a multifaceted and difficult concept considered by researchers in aspects of acoustics, physiology, specifics of opera singing and expressiveness of an opera image. Vocal methodical literature contains certain criteria for definition of type of voice. However, due to the variety of voices, timbres and physical capacities of singers, the individual approach to each voice is necessary. In addition, the voice definition problem can be complicated by defects of sound formation, which only can avoid few beginner vocalists.

The main classification of voices was formed gradually, it developed by the XVII century, in process of development of opera art by vocal researchers a new subtypes in each type of a voice were allocated. 
In the article are shown some of the existing approaches to classification of the types of singing voices which choice was determined by a personal interest and availability of sources to the author.

The separate section of the article is devoted to the classification of opera voices by the Fach system used in Europe, which is somewhat similar to classifications of masters of the Italian school and the Soviet researchers, but it is more differentiated, connects subtypes of a voice not only with characteristics of timbre, but also diverse skills of actors and texture of singers, and also contains examples of the opera parties not extended on the Russian opera scene - which represented the interest to the author ${ }^{8}$.

\section{The used sources}

1. Vishnevskaya G.P. Galina: Istoriya zhizni [Galina: History of life] - M. Novosti, 1991. - $131 \mathrm{p}$.

2. Garbuzov N.A. Process stanovleniya zvukov kak prichina ladovogo dvizheniya. Teoriya mnogoosnovnosti ladov i sozvuchij, ch. 2 [The process of formation of sounds as the cause of the fret movement. The theory of the polybasic nature of modes and consonances, part 2] - Moskva, 1932. - $198 \mathrm{p}$.

3. Garsia M. Sovety po peniyu: Uchebnoe posobie [Singing Tips: Textbook] / perevod N.A. Aleksandrovoj. - Spb.: Planeta muzyki, 2014. - 104 p.

4. Glinka M.I. Zapiski. [Notes]- L.: Muzgiz, 1953. - 284 p.

5. Gontorenko N.B. Sol'noe penie: sekrety vokal'nogo masterstva [Solo singing: the secrets of vocal skill] / N.B. Gontarenko. Izd. 4-e. - Rostov n/D: Feniks, 2008. - 183 s.

6. Gordeeva T.YU. K istokam pevcheskih shkol. Variant klassifikacii. [To the origins of singing schools. Classification option.] Vestnik KemGUKI 23/2013. - s. $176-182$

7. Denisova G.M. Osnovnye postulaty rossijskoj vokal'noj shkoly na sovremennom etape razvitiya muzykal'nogo iskusstva (pevcheskij golos i metodika ego postanovki) [The main postulates of the Russian vocal school at the present stage of development of musical art (singing voice and the method of its staging)] // Vestnik kul'tury i iskusstv 2006. - p. 1 - 19

8. Dmitriev L.B. Osnovy vokal'noj metodiki. [Basics of vocal technique.] - M.: Muzyka, 1968. - 338 p.

9. Evseev F.E. SHkola peniya. Teoriya i praktika dlya vsekh golosov: Uchebnoe posobie. [Singing school. Theory and Practice for All Voices: A Study Guide.] - 2 e izd., ster. SPb.: Izdatel'stvo «Lan'»; Izdatel'stvo «Planeta muzyki», 2015. - 80 p.

10. Zdanovich A.P. Nekotorye voprosy vokal'noj metodiki. [Some questions of vocal technique.] - M.: Muzyka, 1965. - 148 p.

11. Ivanova E.K. Puti formirovaniya i sohraneniya professional'nyh kachestv golosa [Ways of forming and preserving the professional qualities of the voice] // Vestnik kul'tury i iskusstv 2015. - p. $134-139$

\footnotetext{
${ }^{8}$ Перевод аннотации - Т.Ф. Шестакова
} 
12. Kotova R.V. Ispolnitel'skaya kul'tura i formirovanie molodogo pevca artista. [Performing culture and the formation of a young singer - artist.] - M.: Gotika, 2006. $188 \mathrm{p}$.

13. Kotkina I. A. Atlantov v bol'shom teatre: Sud'ba pevca i dvizhenie opernogo stilya. [Atlantov in the Bolshoi Theater: The Fate of a Singer and the Movement of the Opera Style.] - M.: «Agraf», Bol'shoj teatr, 2002. - 336 p.

14. Krouest F. Dzh. Sovety pevcam [Tips for singers] / Per. s angl. E.Sergeevoj: Uchebnoe posobie. - SPb.: Izdatel'stvo «Lan'»; Izdatel'stvo «Planeta muzyki», 2017. $-80 \mathrm{p}$.

15. Lamperti F. Iskusstvo peniya po klassicheskim predaniyam. Tekhnicheskie pravila i sovety uchenikam i artistam: Uchebnoe posobie. 2 - e izd., ispr. [The Art of Singing According to Classical Legends. Technical Rules and Tips for Students and Artists: A Study Guide. 2nd ed., Rev.] - SPb.: Izdatel'stvo «Lan'»; Izdatel'stvo «Planeta muzyki», 2009. - 192 p.

16. Lyush D. V. «Razvitie i sohranenie pevcheskogo golosa». ["Development and preservation of the singing voice."] Kiev: Muz. Ukrajina, 1988. 138 p.

17. Morozov Iskusstvo rezonansnogo peniya. Osnovy rezonansnoj teorii i tekhniki. [The art of resonant singing. Fundamentals of resonance theory and technology] IP RAN, MGK im. P.I. CHajkovskogo, Centr «Iskusstvo i nauka». M., 2002. $496 \mathrm{p}$.

18. Morozov Tajny vokal'noj rechi. [Secrets of vocal speech.] - L.: Izdatel'stvo «Nauka», 1967. 208 p.

19. Nikolaev D. V. Fenomen opernogo golosa [Phenomenon of the operatic voice] // Izvestiya gosudarstvennogo pedagogicheskogo universiteta im. A.I. Gercena 2007. - p. $245-247$

20. Silant'eva I. G. Put' k intonacii: Psihologiya vokal'no - scenicheskogo perevoploshcheniya. [The way to intonation: Psychology of vocal - stage transformation.] - M: KMK, 2009. - 644 p.

21. Stulova G.P. Faktory pedagogicheskogo vozdejstviya na tembr pevcheskogo golosa [Factors of pedagogical influence on the timbre of the singing voice] // Vestnik kafedry YUNESKO «Muzykal'noe iskusstvo i obrazovanie», 2014, p. 90 - 104

22. Teplov B.M. Psihologiya muzykal'nyh sposobnostej [Psychology of musical abilities] / B.M. Teplov. - Moskva - Leningrad: APN RSFSR, 1947. - 336 p.

23. CHishko O.S. Pevcheskij golos i ego svojstva. [Singing voice and its properties.] - L.: Muzyka, 1966. $-50 \mathrm{~s}$.

24. YUsson R. Pevcheskij golos. [Singing voice.] - M.: Muzyka, 1974. - 132 p.

25. Ferril Kyle The Fach System origin, function, and the dangers of perception [Singing voice.] [Elektronnyj resurs] // URL: https://www.academia.edu/ 